\title{
EDUCATIONALLY SUCCESSFUL FEMALE MUSLIM STUDENTS IN PRESENT-DAY MALAYSIA: CHALLENGES, CHANCES AND CHANGE
}

\section{Simon Moses Schleimer}

Die Deutsche Schulakademie, GERMANY

E-mail: mail@simonschleimer.de

Published online: 15 April 2020

To cite this article: Schleimer, S.M. 2020. Educationally successful female Muslim students in present-day Malaysia: Challenges, chances and change. Kajian Malaysia 38(Supp.1): 51-66. https://doi.org/10.21315/km2020.38.s1.4

To link to this article: https://doi.org/10.21315/km2020.38.s1.4

\begin{abstract}
Malaysia, like many other countries experiencing increasing pluralisation and diversification, is facing the challenge of ensuring that its citizens, irrespective of their gender, ethnicity, age, ability, religion and/or other diversity categories, experience equal opportunity in all economic, political, social and cultural fields. The following article, based on episodic interviews conducted with female Malay-Muslim students living in Malaysia, provides an insight into the current reality of young Malay-Muslim women in present-day Malaysia. It highlights the ways in which young Malay-Muslim women negotiate their path in life, as they strive to balance their educational aspirations and personal strivings with traditional family values. The findings of the interviews, analysed using Mayring's "Qualitative Content Analysis" method, reveal the importance of family support for female Malay-Muslim students, especially in cases where family gender norms are challenged.
\end{abstract}

Keywords: education, gender, family, diversity, Malaysia

\section{INTRODUCTION}

This study investigates the impact of gender issues on the lives of female MalayMuslim students in Malaysia. It looks closely at the way in which such students balance their personal lives and educational achievements to overcome potential barriers and discrimination. Based on a qualitative study revolving around a series of episodic interviews with female Malay-Muslim students, and analysed using Mayring's "Qualitative Content Analysis" (Mayring 2015), the study highlights 
the ongoing gender issues in Malaysia and provides a deeper insight into the present-day reality of young female Malay-Muslims in Malaysia. It prepares the ground for further research on Malaysia's achievement of the Sustainable Development Goal (SDG) of "gender equality" proposed by the United Nations, and to which Malaysia is fully committed. To realise the SDG of gender equality, it is essential that gender-sensitive data is collected, gender issues monitored and "evidence-based policies and solutions to achieve gender equality and women's empowerment" (UN Women 2017, n.pp.) are developed. According to Benavot et al. (2016, 319-320), improving the evaluation and monitoring of gender issues in educational contexts involves:

Exploring how ideas and practices relating to gender shape the form and quality of people's educational experiences [...], their educational achievements and their aspirations in the future. It requires examining the extent to which education empowers people to challenge forms of gender discrimination they may experience in families, communities and broader society.

This study questions the static perspectives and ingrained prejudices attributed to "the Muslim women" and their family structures and examines the way in which the social categories of gender, religion, familial background and academic ability are linked. By giving the females a platform to relate their personal narratives and reflect on their present and future lives, the study aims to prevent a hegemonic, or a Eurocentric and/or Anglo-American point of view from colouring the research findings.

\section{FEMALE MUSLIM ADOLESCENTS, RELIGION, EDUCATION AND FAMILY}

Several research studies investigating the way in which young female Muslims have to cope with the requirements expected of them have taken into consideration the diversity categories of gender and religion. Research conducted in the 1990s and early 2000s by Basit (1997), Haw (2011), Khan (2010) and Salih (2004), as well as more recent research by Ghaffar-Kucher (2015) on immigrant and non-immigrant Muslim children, adolescents and young adults, provide a deep insight into the lives of young Muslims in different societies and nations. Many of the studies describe the situations experienced by these young people as challenging and conflicting, implying that the pluralisation processes involved in young Muslims' lives are largely responsible for partly alienating them from their parents. Muslim children, adolescents and young adults all appear to face the challenge of learning how to strike the right balance between familial expectations, social pressure, and their 
own personal wishes for their present and future lives. Religion and education, it appears, are viewed as ways of bridging the gap between the aspirations and lifestyles of young Muslims coupled with their desire to uphold family ties.

The homogenised and one-sided characterisation of Muslim children, adolescents and young adults in many of the studies needs to be viewed critically since very often such studies do not take into account the specific historical backgrounds and/or geographical contexts. It must also be pointed out that the researchers' personal viewpoints, which are always embedded in the dynamics of power and hierarchy, are not always critically reflected (cf. Abu-Lughod 2002; Mohanty 1984; Spivak 1988).

In recent years, studies on Muslim children, adolescents and young adults have begun to address the concept of diversity. This concept has been used prominently, but not exclusively, to emphasise the diversity of all, and to end homogenisation, standardisation and normalisation (Baader 2013, 51). Wimmer (2009) stresses that the perspective of diversity is not focused on simply one category of diversity. It brings:

Differentiations, mode of distinctions and categorizations together and forces us to think about the relationship between them. It thus runs against the tendency to see these different modes of differentiation and categorization as separate domains that are unrelated to each other. It forces us to adopt a holistic perspective on social processes looking from different angles (Wimmer 2009).

By focusing on the relationship between different diversity categories in this study, it was possible to obtain a greater and a more differentiated understanding of the lives of female Malay-Muslim students in Malaysia in order to avoid homogenised attributions. According to Noraini and Nor Diana (2016), the research gap in this field has resulted in a lack of in-depth information regarding the "lived experiences of [Malaysian] men and women within their multiple roles" (p. 731) which is why a special focus on this aspect is so important.

\section{WOMEN IN MALAYSIA}

Following the 1969 race riots, the Malaysian government launched its New Economic Policy (NEP) which gave Malays priority over other ethnicities, especially in employment and education. Educational advantages and special privileges, such as the introduction of quotas for Malays in public universities, suddenly became available to all Malays. Over the past decades there has been a surge of female Muslim participation in education programmes due to the increase in educational provision. Furthermore, all women in Malaysia, irrespective of their 
ethnic background, are regarded as "an important part of addressing the talent gap in Malaysia, to achieve (the country's) socio-economic development objectives" (Economic Planning Unit Malaysia 2015, 3-25) which include, amongst others, industrialisation and the improvement of competitiveness at the international level.

This change is also reflected in the school enrolment figures. The enrolment of Malaysian girls in primary schools remained almost the same between 1970 and $2007 / 2008$, whereas enrolment in secondary schools over the past 40 years saw an increase of about $10 \%$. The increase at post-secondary level was roughly $20 \%$. At university level, there was an almost 30\% enrolment increase, rising from $29.1 \%$ in 1970 to $61.9 \%$ in 2007/2008 (Noraini and Nor Diana 2016, 717). According to Zarinah et al. (2011), the educational success of Malaysian women has led to unparalleled changes in all aspects of their lives, especially with regard to their roles, positions and status in society.

Recent statistics, however, show that women's achievements in Malaysia's educational system are not reflected in the country's labour force. Only 53.6\% of women of working age are in employment (Economic Planning Unit Malaysia 2015, 3-7). Furthermore, the Tenth Malaysia Plan 2010-2015 indicates that many young women leave the labour force after giving birth (Economic Planning Unit Malaysia 2010, 178). These data show that women not only face challenges in the labour market, but still remain an economically disadvantaged group, despite their impressive educational success and the potential they have to offer the labour market.

The study conducted by Noraida et al. (forthcoming) on patriarchy and the attitude towards masculinity in Malaysia attributes the cause of continuing gender inequality to the patriarchal structure of the country. These embedded structures remain a "lived reality for many women in Malaysia" trying to balance their private and public lives. Rossenkhan, Au and Ahmed (2016), in their investigation of Muslim female managers' careers in Malaysia, also reported that balancing a successful career with the role of wife and mother is a constant challenge for many women given the fact that cultural values and conventional gender roles remain strong. Noraini and Nor Diana (2016) likewise state that the "socialization of males and females adheres strictly to traditional cultural values with males being trained to be independent and assertive while females are expected to be effeminate and polite" (p. 717). Azman Azwan Azmawati and Noraida (forthcoming) in their study on gender awareness in Malaysian print media state that "over the years, the patriarchal system in Malaysia has become very prevalent and customary". As a result, women's "voices have not been adequately and promptly recognized" (Azman Azwan Azmawati and Noraida, forthcoming). Another critical factor pointed out by Derichs (2010) and Noraida (2015) is the major disadvantage encountered by Muslim women in Malaysia concerning marriage, divorce, alimony payments and inheritance due to the restrictive interpretation of Islamic law. 
These facts need to be discussed in the light of adat-Malaysia's traditional value system which allows Malay women to become autonomous in different ways. Adat remains an important feature of contemporary Malay society (Wazir Jahan 1992). Another important feature of Malay society is the system of kinship. Carsten (1995) points to the importance of mutual kinship between Malay women and men. She further describes how kinship is fluid and mutable and is not necessarily subject to patriarchal rules. Insofar as both adat and kinship promote the mutual acceptance of the fundamental role of Malay women and men, they can be said to be positive assets for Malay women wishing to retain their independence and remain autonomous in patriarchal, male-dominated social structures. The rapid changes regarding increasing pluralisation and diversification taking place in Malaysia are, however, seen to challenge the importance of both traditional systems and making it increasingly difficult for Malay women to maintain bilateral gender relations.

An exploration of the lives of women in Malaysia, in terms of gender equality, tends to result in contradictory findings. This is especially evident in connection with Malay-Muslim girls and young women, even though Malaysia has made impressive changes regarding gender equality in education. The NEP greatly benefited women, especially young Malay-Muslim women. Today a reversal of the gender gap can be seen with young women clearly outnumbering young men in secondary and tertiary education. Despite this trend, Malaysia still faces challenges in terms of discrimination against women and female empowerment in numerous sectors of Malay society. Here, once again, especially female MalayMuslims are affected because of the more restrictive interpretations of Islamic law and the prevailing patriarchal system in Malay society. The need to achieve gender equality in all areas and at all levels is crucial, especially in the light of Malaysia's commitment to supporting and implementing the SDGs established by the United Nations.

\section{RESEARCH METHODOLOGY}

The qualitative research study discusses how female Malay-Muslim students in Malaysia today balance their personal lives and educational aspirations within the context of familial ties. The 25 episodic interviews carried out during field research focused on the themes of education, female Muslim student experiences in present-day Malaysia, family structures and the students' personal lifestyles. These central themes were converted into guiding questions to ensure uniformity and consistency in all interviews, and also to motivate the interviewees to relate and reflect on their personal stories. In this way, it was possible to gain an insight into the students' individual experiences. The initial plan was to interview both daughters and parents to investigate the viewpoints of both generations. However, 
it proved to be impossible to find parents willing to take part in the study. This problem was discussed at great length with a female Malaysian researcher who mentioned that the parents' hesitance might be caused by the researcher's origin and other interrelated diversity categories such as the researcher's gender, age and social background. Consequently, the Malaysian researcher advised focusing on simply the daughters, instead of pushing the parents for interviews. It was further suggested that the daughters would not trust the researcher and would not open to talk about their education, experiences and family lives if their parents were present at the interviews. Hence the focus of this study was on exclusively female Muslim students.

The strategy for the selection of interviewees was based on the "snowball effect" (Reinders 2012). The sample was enlarged by contacting additional gatekeepers, for example, university staff members who then contacted other female Malay-Muslim students willing to be interviewed. The interviews took place at various locations on the university campus, such as the library, cafés or seminar rooms.

All interviewees were born in Malaysia, attended Malaysian schools and were bachelor or master students at the time of interview. Most of the interviewees were not born in the Malaysian state in which they attended university, and therefore lived away from their families. Despite the distances involved, they all fostered lasting and intense relationships with their family members through modern means of communication, and also made regular visits to the Malaysian hometowns where their families lived. All interviewees came from a range of different familial and socio-economic backgrounds.

The interviews were analysed using Mayring's Qualitative Content Analysis (Mayring 2015) which employs a category system as its central feature. The categories used in this study were developed inductively from the material. In other words, the categories "are coming from the material itself, not from theoretical considerations" (Mayring 2014, 79). In accordance with the rules of procedure outlined by Mayring (2014), the research question was used as a criterion for the selection process in terms of category development. After conducting the interviews, categories were constructed as soon as passages in the interviews were found to fit the research question. If a new passage was found that fitted the research question, it was checked to see if it fell into one of the constructed categories. If no conformity could be recognised, then a new category was formulated. From time to time the category system was revised and modified. In the case of too many categories being formulated, the level of abstraction was defined in more general terms and categories were merged. Finally, main categories and subcategories were formulated. 
Spivak, in her essay "Can the subaltern speak?" (1988), discusses the ethical problems linked to investigating a different culture - or to be more precise - the problems encountered by privileged white Western males who investigate other cultures using Eurocentric concepts and frameworks to speak for individuals without allowing the individuals to speak for themselves (cf. Said 1978; Bhabha 2000). Spivak's critique is based on the perspective of diversity and positions itself against homogenisation and essentialisation.

With regard to the research topic, the research questions and the research design were not only discussed critically during the field research but were also partly modified during a number of meetings with the researchers in Malaysia. In addition, recent experiences, challenges and initial interpretations of the interviews were discussed in depth with the Malaysian researchers and subsequently reviewed which led to new perspectives being gained. A second coder was engaged to test the inter-coder reliability of the coded interviews. This process "contributes to the intersubjectivity of the procedure" (Mayring 2014, 40). The second coder, a colleague from a different background to the researcher, took a different perspective on the interviews. All the categories were discussed with the second coder and modified whenever necessary.

\section{RESULTS}

This article focuses on the educational experiences and family lives of the interviewees. The main focus will be on the main category "family support" and the subcategories "supportive and empowering", "supportive but predefined" and "non-supportive". Each subcategory will be presented by giving insights into the individual cases. Even though the students' experiences are all unique, the interviews display certain similarities in the subcategory under which they are listed. Accordingly, each individual case presented may be considered to be representative of the category's main characteristics which will be listed after each individual case has been presented. The subsequent discussion focuses on the role played by the family in the female students' lives. It also discusses the ways in which the students initiate change within their familial structures to emancipate themselves within contemporary Malaysian society. 
Table 1: Main category "family support"

\begin{tabular}{ccc}
\hline Main category & Subcategory & Number of mentions \\
\hline Family support & Supportive and empowering & 15 \\
& Supportive but predefined & 9 \\
& Non-supportive & 1 \\
\hline
\end{tabular}

\section{Supportive and Empowering}

Nayla was 21 years old at the time of the interview. She has a younger brother and an older sister. She is the first daughter of her family to study at university. She was born in a suburban town in Malaysia; her father and her mother work in a small shop near their house. Nayla moved out of the family home when she started her studies. The move changed her life enormously. She talks about the fact that she lives a different life in comparison to her parents because of her new surroundings. She remarks that she has become a very open-minded person since she became acquainted with fellow students from different backgrounds and different nationalities. Nevertheless, she still maintains a close relationship with her parents and siblings and visits them almost every weekend. She says that her parents are curious to find out how her life has changed and that they are proud of her and her educational success. She feels fully supported by them. In return, Nayla wants to make them proud and happy in acknowledgement of their support. She says:

They don't care if I want to become a teacher or anything else I want. They just want me to study. So, I think that by studying, I will satisfy them. They always support me. They don't care and say, "if you choose this and you're happy, then we are happy, too." I am very thankful because they are my strongest supporters! I want to make them proud.

Nayla says that she has become a role model for her younger brother and her older sister. She supports her brother in school and has convinced her sister to continue her studies. In addition, she has gradually become financially independent of her family by selling headscarves to her fellow students which means she is no longer reliant on her parents' financial support.

Fifteen of the interviewees highlight the fact that they receive parental support and recognition of their educational aspirations. In addition to specific means of support, such as payment of extra tuition fees, the interviewees refer to the emotional support they receive. They stress the fact that their parents did not determine their choice of specialisation at school, i.e., in the arts or sciences or stipulate which university study course they should take. The supportive 
and empowering parents tend to have no specific expectations regarding their daughters' education and even approve of their daughters' educational choices. As a result, their daughters feel grateful towards them because they feel that their parents believe in them and value their aspirations. Moreover, the daughters experience a sense of independence plus a feeling of responsibility for their chosen way of life and education. They feel free to follow their dreams and aspirations and emancipate themselves from their families without fear of losing the close ties that bind them to their parents and siblings.

\section{Supportive but Predefined}

At the time of the interview Hafiza was 22 years old. She and her younger sister were born into a wealthy family in a Malaysian city. Her father is a manager in a medium-sized company, and her mother is a teacher. Hafiza's parents seem to have already planned their daughter's life and have a clear vision regarding Hafiza's education and future. Hafiza says:

My father wanted me to be a doctor. You know...to study medicine. In form three I got the results for science, so in form four he decided that I have to take the science stream. I wasn't fully interested...So, I did not do well in my SPM. So, from that I told my father that I wanted to change from science to arts because my dream is not to become a doctor, but he did not let me change. He said to me, "what do you want to be if you take arts stream?" Because for him arts stream doesn't go anywhere... My mum supports him. She thinks the same.

Although Hafiza was not allowed to follow her own educational dreams, she mentions in the interview that she is happy with her course of study since she is convinced that her parents only want the best for her and her future life. She feels especially grateful because her parents are proud of her and her educational achievements. She also says in the interview that both of her parents wanted to become doctors but were unable to fulfil their dreams. For this reason, she feels proud to be able to fulfil her parents' dreams and is happy to see them pleased. This, in turn, makes it easier for her to follow their wishes. Additionally, Hafiza says that she accepts her parents' wishes because by following their plan she can find diverse ways to fulfil her own aspirations in other aspects of life. She says:

I'm happy and can arrange my life around their wishes because I know that my parents only want the best for me. And because I do so, I am allowed to go abroad to study one year outside Malaysia. I applied for a scholarship. It was like a "small deal" between me and my parents (laughing). 
Nine students indicated that while their parents supported them on their educational journey, they did not take their daughters' individual interests into consideration. The parents themselves decided which stream their daughters chose at school, which university they later attended and which course of study they followed. One reason for this might be because they wanted their daughters to realise their own unfulfilled dreams. Their daughters accepted their parents' wishes without objection because they knew they could find diverse ways of emancipating themselves from their parents in other spheres of life. As a result, they started negotiating with their parents over various issues and subsequently initiated changes within the family structure.

\section{Non-supportive}

Aishyah was 21 years old at the time of the interview. She is one of six children from an underprivileged family living in a rural area of Malaysia. At the beginning of the interview, she mentioned that her parents do not support her education in any way. Although it was important for them that she graduates from school, they did not want her to continue her studies. Instead, they expected her to marry and start a family since they consider educational success and an academic career to be unimportant. Aishyah states:

My father doesn't expect me to study. He asked me, "Why do you want to study? Not necessary for you. Go and find a husband....That's our culture. But I am smart and if I work hard, if I have good ideas, I can get any position I want.

Aishyah's desire for educational success only strengthened her determination to study. After graduating from school, she applied to university after clashing with her parents about her future. In the end, she convinced them to allow her to study by promising to marry on completion of her bachelor's degree. However, her educational aspirations have once again prevailed over her parents' wishes. She now plans to continue her studies and do a master's degree. She is following her educational dreams and cannot accept her parents' wishes. She says:

"Why should I marry now? I am not done with my education! It is a lot of work and I have to do everything by myself because my parents want to see me fail to get me married."

Aishyah explains that she can partly understand her parents' attitude since she is the first daughter of her family to study. She thinks that her parents fear societal developments and want to protect her and keep her away from influences they "consider as bad", as Aishyah terms it. It appears that trying to fulfil her own 
dreams puts her under a lot of pressure because she constantly must prove to her parents that her decision to study was right. She says she feels like "the rebel of the family" and feels responsible for changing her family's structures by encouraging her siblings to follow her chosen path. She hopes that her parents will start supporting her siblings based on her educational success and the positive experiences they have had with her. Aishyah is confident that one day her parents will see the benefits brought by studying, especially when she earns her own money and is able to help her parents financially. Even if Aishyah feels unsupported, she does not turn away from her parents because she "wouldn't know how to make a life without them". Her response to the question of how she copes with conflicts with her parents was as follows:

Religion makes me feel calm. Because, sometimes studies make me feel stressed out. And if I don't have any motivation or have trouble with my parents, we talk about religion to motivate us.

Only one interviewee does not receive any educational support from her parents. Instead, her parents want her to marry after graduating from school. The interviewee finds different ways of negotiating with her parents to be able to follow her own interests. She only partly emancipates herself from her family and is thus able to keep the family peace by staying close to them without feeling alienated. An important link between daughter and family seems to be their common religion. Despite everything, the interviewee seems to be changing the family structure slightly in so far as she is paving the way for her younger siblings to have the chance to follow their dreams.

\section{DISCUSSION}

The three previously mentioned subcategories illustrate the diversity of the lives of Malaysian female students from different socioeconomic and familial backgrounds and unequal starting points. Despite this, certain similarities between the interviewees can be observed in all subcategories.

For instance, education and educational success is important for the young females and their parents in both the categories "supportive and empowering" and "supportive but predefined". The daughters feel grateful for the opportunities provided by their parents, irrespective of whether the parents determine the daughters' choice of education. In return, the daughters feel motivated to fulfil their parents' expectations and become successful in order to "give something back", as Hafiza puts it in her interview. The young female students' education is not just an individual project but a family project. Furthermore, educational success does 
not seem to be possible for the students without their parents' support. In contrast, education for the interviewee in the subcategory "non-supportive" is only important for the interviewee herself since her parents only want her to get married. Despite parental objection, she stands her ground and fulfils her educational dreams.

The interviewees of all three subcategories were exposed to different value systems and more international and pluralised surroundings when they left home to study at university. Encounters with international students on the university campus, as well as an ethnically diverse Malaysian student population, provided many opportunities for the interviewees to explore different lifestyles and different world views. This causes their lives to change rapidly and become more dynamic and diversified. As a result, the female students began to develop plans for the future and follow their own goals: Hafiza is going to go abroad to study, Nayla has become a female entrepreneur and Aishyah's educational success has helped her become more independent of her parents and their plans. Gradually, they have all become more autonomous and partly alienated themselves from their parents' lives. Despite this, they do not view their way of living and their families' way of living as highly contradictory or challenging. Even Aishyah stresses several times in the interview that she does not want to leave her family or break with family ties. However, sometimes differences arise which occasionally lead to conflicts between the interviewees and their parents. Due to the interviewees' ability to find various ways of merging their own aspirations with their parents' expectations they are generally able to maintain intergenerational harmony and come to an agreement with their family.

The interviewees seem to be able to undergo these processes of individualisation mainly because of their acceptance of family norms and values. They feel supported by their parents even if they have to first struggle to follow their dreams and aspirations, as Aishyah's interview comments reveal. All interviewees consider their families' traditions, values and experiences to be identity markers and the source of their individual development. They keep the ties to their parents strong, yet are simultaneously able to emancipate themselves. By initiating changes and transformations within their families, they create more autonomy for themselves and their siblings. All interviewees, however, attach great importance to intergenerational harmony. One reason for these close ties between parents and children might be found in the Malay system of "kinship" according to Carsten (1995). The author characterises Malay kinship, the constant loving relations within the family, inner familial harmony, the intense relationships between family members as a fluid process intended to help a family member become complete. This very unique concept of "kinship" in Malay tradition can be still found today in Malay families. Probably the families of the interviewees also want their own children to embody this concept which is why they attach such importance to maintaining close family ties. 


\section{CONCLUSION}

The qualitative research study investigated the diversity of the lives of female Malay-Muslim students in Malaysia by focusing on the questions of how they negotiate their lives and educational aspirations within the context of their family structures. The study demonstrates that the diversity categories of gender, family socioeconomic background and academic ability, as reflected in the female students' educational success, are all linked in Malaysia in different ways.

Recent studies have proven that achieving gender equality remains a challenge given that discrimination against women still prevails in various spheres of social life in Malaysia (cf. Noraini and Nor Diana 2016; Azman Azwan Azmawati and Noraida, forthcoming). The diversity category of gender, therefore, seems to be restrictive for women and girls in Malaysian society. However, the interviews indicate that gender in Malaysia is less restrictive when it comes to academic ability and socioeconomic background. A higher parental socioeconomic status plus educational success can be a resource, as well as a form of capital, in the pursuit of autonomy, the fulfilment of personal dreams and wishes and the desire to maintain strong family ties.

Benavot et al. (2016) raise an important point concerning education and gender equality in the context of the previously mentioned SDGs. They point out that while there is specific mention of gender in the SDG with regard to education, it "mainly appears in terms of gender parity" (p. 319), while "[g]ender equality is obviously absent as a target in SDG 4" (p. 319). The findings of this study confirm the fact that despite female educational achievements being a success story for almost 40 years in Malaysia, full gender equality in all spheres of society is still an important goal because of the many barriers that continue to exist.

This study offers a better understanding of the lives of female MalayMuslim students, their educational ambitions and familial structures by taking a closer look at their educational achievements and aspirations. The results of this study, independent of the academic success of the young females, can serve to highlight existing gender issues, close research gaps and even form a basis for further research on gender and education in Malaysia. Further research on intergenerational dynamics from the perspectives of both parents and their daughters would also be constructive. Longitudinal research designs would improve our understanding of how female Malay-Muslims negotiate their lives long term and provide an insight into how they cope with discrimination when they enter the labour market. Additionally, the findings of the study can help to develop policies to address gender issues in Malaysia.

In a wider context, this study challenges the static perspectives and ingrained prejudices that depict Muslim females as victims of a patriarchal family, suppressed by male family members, and unable to live a self-determined life. 
This study reveals a different picture, namely the diversity of the lives of female Malay-Muslim students in Malaysia. The study was conducted in such a way as to allow the interviewees to be embedded into the concept of the study. Instead of talking about female Malay-Muslim students, talking with female Malay-Muslim students was the guiding principle. Despite the fact that the lifestyles of female Malay-Muslims appear diverse and complex, it must be noted they are actually not so greatly different from the lifestyles of many other female (Muslim) students all over the world.

\section{ACKNOWLEDGEMENTS}

The research study was conducted in the context of the research and development project "Pupils' Diversity and Success in Science Education in Germany and Malaysia" at the Friedrich-Alexander-University Erlangen-Nuernberg. The project was funded by the German Academic Exchange Service (DAAD) as part of the programme "Higher Education Dialogue with the Muslim World".

\section{REFERENCES}

Abu-Lughod, L. 2002. Do Muslim women really need saving? Anthropological reflections on cultural relativism and its others. American Anthropologist 103(3): 783-790. https://doi.org/10.1525/aa.2002.104.3.783

Azman Azwan Azmawati and Noraida Endut. Forthcoming. Gender awareness education in the Malaysian print media: Advancing or repeating. In Diversity education in a global society - national concerns and transnational influences, eds. A. Rakhkochkine and S. M. Schleimer. Erlangen: FAU Press.

Baader, M. 2013. Diversity education in den erziehungswissenschaften - "diversity" as a buzzword. In Diversity education: Zugänge - perspektiven - beispiele, eds. K. Hauenschild, S. Robak and I. Sievers, 38-60. Frankfurt: Brandes \& Apsel.

Basit, T.N. 1997. "I want freedom, but not too much": British Muslim girls and the dynamism of family values. Gender \& Education 9(4): 425-440. https://doi.org/10.1080/09540259721178

Benavot, A., N. Bella, P. Joshi and A. McWilliam. 2016. From gender parity to gender equality: Situating gender in the monitoring of international education targets. Bildung und Erziehung 3(69): 305-324. https://doi.org/10.7788/bue-2016-0305

Bhabha, H. 2000. Die verortung der kultur. Tübingen: Stauffenburg.

Carsten, J. 1995. The heat of the hearth: The process of kinship in a Malay fishing community. Oxford: Oxford University Press.

Derichs, C. 2010. Islamische familiengesetze: Vom zankapfel zum reformprojekt. In Islam und staat in den ländern südostasiens, eds. F. Schulze and H. Warnk, 127-147. Wiesbaden: Harrassowitz. 
Economic Planning Unit Malaysia. 2010. Tenth Malaysia Plan 2011-2015. https://www. pmo.gov.my/dokumenattached/RMK/RMK10_Eds.pdf (accessed March 2018).

2015. Eleventh Malaysia Plan 2016-2020. https://policy.asiapacificenergy.org/ sites/default/files/11th\%20Malaysia\%20plan.pdf (accessed March 2018).

Ghaffar-Kucher, A. 2015. "Narrow-minded and oppressive" or a "superior culture"? Implications of divergent representations of Islam for Pakistani-American youth. Race Ethnicity and Education 18(2): 1-34. https://doi.org/10.1080/13613324 .2014.889111

Haw, K. 2011. The "changing same" of an "in-between" generation: Negotiating identities through space, place and time. Discourse: Studies in the Cultural Politics of Education 32(4): 565-579. https://doi.org/10.1080/01596306.2011.601553

Khan, S.S. 2010. Education and agency: Muslim women and the tensions of traditional and modern expectations. PhD diss., School of Education, Harvard University.

Mayring, P. 2014. Qualitative content analysis: Theoretical foundation, basic procedures and software solution. http://nbn-resolving.de/urn:nbn:de:0168-ssoar-395173 (accessed November 2018).

2015. Qualitative inhaltsanalyse: Grundlagen und techniken. Weinheim: Beltz.

Mohanty, C.T. 1984. Under western eyes: Feminist scholarship and colonial discourses. Boundary 12(3): 333-358. https://doi.org/10.2307/302821

Noraida Endut, Azman Azwan Azmawati, Intan Hasyimah Mohd Hashim and Nor Hafizah Selamat. Forthcoming. Discussing gender in a university setting: Drawing from conversations amongst women and men in a Malaysian public university. In Diversity education in a global society - national concerns and transnational influences, eds. A. Rakhkochkine and S.M. Schleimer. Erlangen: FAU Press.

Noraida Endut. 2015. Reconstructing justice for women in the courts: An investigation of Syariah court processes in Malaysia. In Gendered entanglements: Revisiting gender in rapidly changing Asia, eds. R. Lund, P. Doneys and P.B. Resurrección, 263-293. Copenhagen: NIAS Press.

Noraini M. Noor and Nor Diana Mohd Mahudin. 2016. Work, family and women's well-being in Malaysia. In Handbook in well-being of working women, eds. M.L. Connerley and J. Wu, 717-734. Wiesbaden: Springer-VS. https://doi .org/10.1007/978-94-017-9897-6_40

Reinders, H. 2012. Qualitative interviews mit jugendlichen führen: Ein leitfaden. München: Oldenbourg Verlag. https://doi.org/10.1524/9783486717600

Said, E. 1978. Orientalism. New York: Pantheon.

Salih, R. 2004. The backward and the new. National, transnational and post-national Islam in Europe. Journal of Ethnic and Migration Studies 30(5): 995-1011. https://doi.org/10.1080/1369183042000245660

Spivak, G.C. 1988. Can the subaltern speak? In Marxism and the interpretation of culture, eds. C. Nelson and L. Grossberg, 66-111. Chicago: University of Illinois Press. https://doi.org/10.1007/978-1-349-19059-1_20

UN Women. 2017. Spotlighting gender data at the first-ever UN World Data Forum. https://www.unwomen.org/en/news/stories/2017/1/announcer-gender-data-at -the-first-ever-un-world-data-forum (accessed March 2018). 
Wazir Jahan Karim. 1992. Women and culture: Between Malay adat and Islam. Boulder: Westview Press.

Wimmer, A. 2009. Diversity interview. https:/www.mmg.mpg.de/65148/interview-with -andreas-wimmer (accessed March 2018).

Zarinah Mahari, Wan Rosilda Othman, Noor Masayu Mhd Khalili, Sabariah Esa and Nadia Miskiman. 2011. Demographic transition in Malaysia: The changing roles of women. http://www.cwsc2011.gov.in/papers/demographic_transitions/ Paper_1.pdf (accessed March 2018).

Zubeida Rossenkhan, Au We Chan and Pervais K. Ahmed. 2016. Complexities of Muslim women managers' careers: An identity perspective. Paper presented at Proceedings of 3rd KANITA Postgraduate International Conference on Gender Studies, Centre for Research on Women and Gender (KANITA), Pulau Pinang. 16-17 November. 